\title{
Studi Komunitas Makrozoobenthos di Kawasan Hutan Mangrove Pulau Penyu, Tanjung Benoa, Bali
}

\author{
Elok Faiqoh*, Henny Hayati, Kadek Yudiastuti \\ Program Studi Ilmu Kelautan, Fakultas Kelautan dan Perikanan, Universitas Udayana, Kampus UNUD Bukit Jimbaran, Badung, Bali, Indonesia \\ *Penulis koresponden. Tel.: +62-361-702-802 \\ Alamat e-mail: elok.widodo@gmail.com
}

Diterima (received) 13 Februaari 2016; disetujui (accepted) 28 Mei 2016; tersedia secara online (available online) 31 Mei 2016

\begin{abstract}
Mangrove in marine ecosystem have function to help continuing food chain directly, provide food for benthics organism, include macrozoo and microzoo, and ephiphyte and indirectly as habitat, nursery ground and spawning ground (Nontji (1993), Valiela et al, (2001). This research analyzed macrozoobenthics community in mangrove forest, Penyu Island, Tanjung Benoa, and counting correlation between mangrove density and macrozoobenthics abundance. 4 mangroves species (Bruguiera gymnorrhiza, Rhizopora mucronata, Rhizopora stylosa dan Sonneratia alba) and 22 macrozoobenthics genus (Cvpraeidae, Naticidae, Cerithiidae, Mathildidae, Mitridae, Columbellidae, Buccinidae, Neritidae, Fasciolariidae, Smaragdinellidae, Littorinidae, Trochidae, Costellariidae, Terebridae, Opisthobranchia, Pyramidellomorpha, Littorinidae, Conidae, Thaididae, Potamididae, Turritellidae, Nassariidae) were identified from 3 stasions over the Island. Rhizopora stylosa have the highest importance index in Penyu Island mangroves community and than Bruguiera gymnorrhiza. The highest abundance documented in station 1 for $385.2 \mathrm{ind} / \mathrm{m}^{2}$ and then station 2 for 271.58 $\mathrm{ind} / \mathrm{m}^{2}$ and the lowest is station $3247.71 \mathrm{ind} / \mathrm{m}^{2}$. Cerithium $\mathrm{sp}$ recorded as dominant species and Turritella cochlea and Cyprae kieneri as inferior species. Macrozoobenthos community in Penyu Island is being stable base $\mathrm{d}$ on high diversity index, moderate eveness index and low dominance index. The regression equation acquired $\mathrm{Y}=-60.524 \mathrm{X}+119.94$ and revealed correlation $40.05 \%$ and explain $16.04 \%$ macrozoobenthics varians. From the study inconclusive there are no correlation between mangroves density and macrozoobenthics abundance.
\end{abstract}

Keywords: macrozoobenhtics, mangroves, penyuisland, tanjung benoa

\begin{abstract}
Abstrak
Peranan mangrove di perairan laut membantu perputaran mata rantai makanan baik secara langsung maupun tidak langsung. Secara langsung yaitu dengan menyediakan makanan berupa serasah daun bagi organisme penetap (Nontji, 1993) dan secara tidak langsung sebagai tempat tinggal, pemijahan dan asuhan yang terlindung (Valiela et al, 2001) diantaranya biota penempel pada pohon, membenamkan diri dan biota yang merangkak didasar perairan, semua biota ini merupakan komunitas makrozoobenthos (Tapilatu dan Pelasula, 2012). Penelitian ini bertujuan untuk menganalisis komunitas makrozoobenthos di kawasan Hutan Mangrove, Pulau Penyu dan melihat hubungan antara makrozoobenthos dan mangrove. Data didapatkan 4 jenis mangrove sejati yaitu Bruguiera gymnorrhiza, Rhizopora mucronata, Rhizopora stylosa dan Sonneratia alba.Indeks Nilai Penting terbesar didapatkan pada jenis Rhizopora stylosa pada stasiun 2, kemudian Bruguiera gymnorrhiza di stasiun 1dan terbesar ketiga Rhizopora mucronata pada stasiun 3 . Jenis makrozoobenthos teridentifikasi sebanyak 44 jenis makrozoobenthos yang tersebar pada 3 stasiun dalam 9 titik. Ke 44 jenis makrozoobentos ini terdiri dari 22 genus terdiri dari Cvpraeidae, Naticidae, Cerithiidae, Mathildidae, Mitridae, Columbellidae, Buccinidae, Neritidae, Fasciolariidae, Smaragdinellidae, Littorinidae, Trochidae, Costellariidae, Terebridae, Opisthobranchia, Pyramidellomorpha, Littorinidae, Conidae, Thaididae, Potamididae, Turritellidae, Nassariidae. Kelimpahan makrozoobenthos tertinggi pada stasiun I yaitu $385.2 \mathrm{ind} / \mathrm{m}^{2}$, lalu stasiun II yaitu $271.58 \mathrm{ind} / \mathrm{m}^{2}$ dan terendah pada stasiun III yaitu $247.71 \mathrm{ind} / \mathrm{m}^{2}$. Kelimpahan tertinggi pada ketiga stasiun berada pada spesies Cerithium sp kelimpahan terendah berada pada spesies Turritella cochlea dan Cyprae kieneri. Hasil indeks keanekaragaman yang tinggi, keseragaman sedang dan dominansi rendah menunjukkan bahwa kondisi komunitas makrozoobenthos di Pulau Penyu menuju kestabilan. Kondisi lingkungan di Pulau Penyu mendukung kehidupan makrozoobenthos, khususnya jenis gastropoda. Persamaan regresi didapatkan $\mathrm{Y}=-60.524 \mathrm{X}+119.94$ dengan korelasi 40,05\% dan dapat menjelaskan 16,04\% keragaman makrozoobenthos. Dari penelitian ini disimpulkan kerapatan pohon mangrove tidak berpengaruh nyata terhadap kepadatan makrozoobenthos.
\end{abstract}

Kata Kunci:macrozoobenhtos, mangrove, pulau penyu, tanjung benoa

\section{Pendahuluan}

Pulau Penyu terletak di sebelah Timur, Tanjung Benoa, Bali. Penamaan Pulau Penyu berdasarkan aktifitas warga sekitar yang menggunakan daerah tersebut sebagai tempat penangkaran penyu. Hutan mangrove di kawasan Pulau Penyu, saat ini mempunyai luas sekitar 4 hektar dan merupakan bagian dari komunitas mangrove Teluk Benoa. Komunitas mangrove di Teluk Benoa memiliki 11 (sebelas) jenis vegetasi mangrove sejati dan 1 jenis 
mangrove ikutan yaitu Waru Laut (Thespesia popunema) (Wiyanto dan Faiqoh, 2015). Hutan mangrove merupakan komunitas tanaman hutan tropis dan subtropis yang tumbuh di daerah pantai dan muara sungai sehingga mampu beradaptasi dengan salinitas tinggi. Kawasan hutan mangrove di daerah Pulau Penyu telah mengalami penurunan kualitas seperti banyaknya sampah dan limbah yang diakibatkan oleh adanya beberapa aktivitas manusia.

Peranan mangrove di perairan laut membantu perputaran mata rantai makanan baik secara langsung maupun tidak langsung. Secara langsung yaitu dengan menyediakan makanan berupa serasah daun bagi organisme penetap (Nontji, 1993) dan secara tidak langsung sebagai tempat tinggal, pemijahan dan asuhan yang terlindung (Valiela et al, 2001) diantaranya biota penempel pada pohon, membenamkan diri dan biota yang merangkak didasar perairan, semua biota ini merupakan komunitas makrozoobenthos (Tapilatu dan Pelasula, 2012). Timbal balik yang diberikan oleh komunitas makrozoobenthos adalah membantu mangrove dalam mendapatkan nutrient dengan cara membantu proses dekomposisi material organic (Ulfah dkk., 2012) menjaga keseimbangan ekosistem mangrove, sehingga makrozoobenthos dapat digunakan untuk keseimbangan lingkungan.

Penelitian ini bertujuan untuk menganalisis komunitas makrozoobenthos di kawasan Hutan Mangrove, Pulau Penyu dan melihat hubungan antara makrozoobenthos dan mangrove. Hasil penelitian ini diharapkan dapat membantu keberlanjutan ekosistem mangrove di Pulau Penyu, Tanjung Benoa.

\section{Metode Penelitian}

\subsection{Waktu dan lokasi penelitian}

Penelitian pengambilan sampel dilapangan dilakukan pada tanggal 14 Oktober 2015. Wilayah atau lokasi penelitian terletak di Pulau Penyu Tanjung Benoa, termasuk dalam wilayah Kabupaten Badung, Propinsi Bali (Gambar 1).

\subsection{Pengambilan sampel}

\subsubsection{Makrozoobenthos}

Pengambilan sampel dilapangan menggunakan pipa paralon berdiameter $11 \mathrm{~cm}$ dan panjang $20 \mathrm{~cm}$, sedangkan penentuan titik sampling dengan metode transek. Pengambilan makrozoobenthos di ekosistem mangrove terdapat pada 3 stasiun dengan jarak perstasiun 100 meter. Tiap stasiun terdiri dari 3 titik pengambilan sampel. Pengambilan sampel dilakukan dengan menancapkan pipa paralon pada titik sampling. Makrozoobenthos yang ada di dalam pipa paralon diambil dan didata. Sampel makrozoobenthos yang berada di dalam pipa paralon kemudian dimasukan ke dalam kantong plastik dan diberikan lebel yang sesuai dengan titik dan stasiun pengamatan. Makrozoobenthos yang telah diambil kemudian dicuci bersih dan disaring dengan menggunakan ayakan untuk memisahkan spesies makrozoobentos dengan pasir. Letakan makrozoobenthos yang telah dicuci dan disaring di atas nampan, sertakan label pada nampan tersebut yang bertujuan sebagai penanda dan tunggu hingga sampel dalam keadaan kering. Sampel diidentifikasi menggunakan lup dan dengan bantuan buku identifikasi. Data hasil indentifikasi di catat berdasarkan jumlah dan jenisnya.

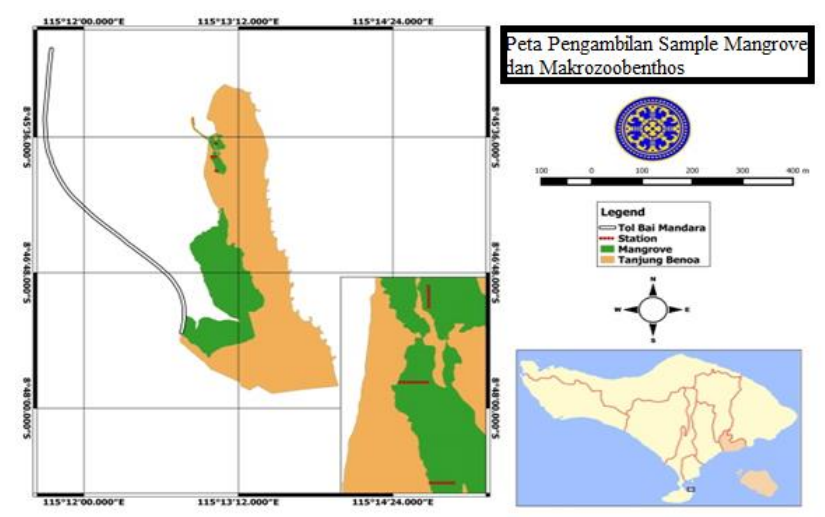

Gambar 1.Peta lokasi studi dan stasiun pengambilan sampel

\subsubsection{Mangrove}

Pengambilan sampel dilakukan di 3 titik stasiun yang diambil di lokasi penelitian. prosedur pengambilan data dan pengamatan vegetasi mangrove disesuaikan dengan metode yang telah dipublikasikan oleh Bengen (2001)

\subsection{Analisis Data}

2.3.1. Kelimpahan Makrozoobenthos dan Kerapatan Mangrove

$$
D i=\frac{n i}{A}
$$

Keterangan :

$\mathrm{R}=$ Kelimpahan / Kerapatan jenis ke-i (spesies).

$\mathrm{ni} \quad=$ Jumlah individu setiap jenis (ind)

A $=$ Luas area plot pengamatan $(\mathrm{m} 2)$

2.3.2. Kelimpahan Makrozoobenthos dan Kerapatan Mangrove

a. Kerapatan Relatif Jenis (Rdi) adalah perbandingan antara jumlah tegakan jenis ke-I (ni) dan jumlah tegakan seluruh jenis $\left(\sum \mathrm{n}\right)$.

$R d_{i}\left(\frac{n i}{\Sigma n}\right) \times 100$

b. Frekuensi Jenis $(F i)$ adalah peluang ditemukannya jenis ke- $I$ dalam petak contoh yang diamati.

$F_{i}=\frac{p_{i}}{\sum p}$

Keterangan:

$\mathrm{p}_{i}:$ Petak contoh/plot

$\sum$ p: Jumlah total petak contoh/plot yang diamati.

c. Frekuensi Relatif Jenis (Rfi) adalah perbandingan antara frekuensi jenis $I(\mathrm{Fi})$ dan jumlah frekuensi untuk seluruh jenis $\left(\sum \mathrm{f}\right)$.

$R f_{i}=\frac{f_{i}}{\sum f} \times 100$ 
d. Penutupan Jenis $\left(\mathrm{C}_{i}\right)$ adalah luas pentupan jenis $I\left(n_{i}\right)$ dalam suatu unit area.

$C_{i}=\frac{\sum B A}{A}$

e. Penutupan Relatif Jenis (Rci) adalah perbandingan antara luas area penutupan jenis $I\left(\mathrm{C}_{i}\right)$ dan luas total area penutup untuk seluruh jenis $\left(\sum \mathrm{c}\right)$.

$R c_{i}=\frac{c_{i}}{\sum c} \times 100$

f. Jumlah Nilai Kerapatan Relatif Jenis (Rdi) Frekuensi Realatif Jenis (Rfi) dan Penutupan Realatif Jenis (Rci) menujukan Indeks Nilai Penting (INP) untuk masingmasing jenis.

$I N P=R d_{i} \times R f_{i} \times R c_{i}$

Nilai Penting suatu jenis berkisar antara 0-300. Indeks ini memberikan suatu gambaran mengenai pengaruh atau peranan suatu jenis tumbuhan mangrove dalam suatu komunitas.

\subsubsection{Indeks Ekologi}

a. Indeks Keanekaragaman

Indeks keanekaragaman dihitung dengan rumus ShannonWiener (Odum, 1993)

$$
\mathrm{H}^{\prime}=-\sum\left(\frac{\mathrm{ni}}{\mathrm{N}}\right) \ln \left(\frac{\mathrm{ni}}{\mathrm{N}}\right)
$$

Keterangan :

$$
\begin{aligned}
\mathrm{H}^{\prime} & =\text { Indeks keanekargaman } \\
\mathrm{ni} & =\text { Jumlah individu } \\
\mathrm{N} & =\text { Jumlah total individu }
\end{aligned}
$$

Kisaran nilai Indeks Keanekaragaman Shannon-Wiener (1949 dalam Dahuri 1994) dapat diklasifikasikan sebagai berikut :

- $\mathrm{H}^{\prime}<1$ : Keragaman spesiesnya / genera rendah, penyebaran jumlah individu tiap spesies atau genera rendah, kestabilan komunitas rendah dan keadaan perairan telah tercemar berat.

- $1<\mathrm{H}^{\prime}<3$ : Keragaman sedang penyebaran jumlah individu tiap spesies atau genera sedang, kestabilan komunitas sedang dan keadaan perairan telah tercemar sedang.

- H'> 3 : Keragaman tinggi, penyebaran jumlah individu tiap spesies atau genera tinggi dan perairannya masih bersih/ belum tercemar

b. Indeks Keseragaman

Indeks keseragaman digunakan menurut (Brower et al., 1998) yang digunakan adalah :

$$
\mathrm{E}=\frac{\mathrm{H} \prime}{\ln \mathrm{S}}
$$

\section{Keterangan :}

$\mathrm{E} \quad=$ Indeks keseragaman jenis

$\mathrm{H}^{\prime} \quad$ = Indeks keanekaragaman jenis

$\mathrm{S} \quad=$ Jumlah jenis spesies

Nilai Indeks Keseragaman berkisaran antara 0-1, semakin kecil nilai E (mendekati 0), keseragaman semakin kecil yang berarti penyebaran jumlah individu setiap jenis tidak sama ada kecenderungan terjadi dominasi oleh jenis-jenis tertentu. Semakin besar nilai E (mendekati i) menujukkan keseragaman populasi yang tinggi, jumlah individu setiap jenis dapat dikatakan sama atau tidak jauh berbeda. Kisaran nilai indeks keseragaman adalah :

$$
\begin{array}{ll}
\mathrm{E}<0,4 & : \text { Keseragaman rendah } \\
0,4 \leq \mathrm{E} \leq 0,6 & : \text { Keseragaman sedang } \\
\mathrm{E}>0,6 & : \text { Keseragaman tinggi }
\end{array}
$$

\section{c. Indeks Dominansi}

Indeks domonansi dihitung dengan rumus dominansi Simpson (Odum, 1993).

$$
\begin{aligned}
& C=\sum\left(\frac{n i}{N}\right)^{2} \\
& \text { Keterangan : } \\
& \text { C } \quad=\text { Indeks dominansi } \\
& \text { ni } \quad=\text { Jumlah individu setiap jenis } \\
& \mathrm{N} \quad=\text { Jumlah total individu }
\end{aligned}
$$

Nilai indeks dominasi berkiasar antara $0-1$. Jika nilai C mendekati 0 , berarti tidak ada jenis yang mendominansi. Sedangkan jika nilai $\mathrm{C}$ besar (mendekati) berati ada jenis yang mendominansi. Kisaran nilai indeks dominansi dapat diklasifikasikan sebagai berikut :

$$
\begin{array}{ll}
0<\mathrm{C}<0,3 & : \text { Dominansi rendah } \\
0,3<\mathrm{C} \leq 0,6 & : \text { Dominansi sedang } \\
0,6<\mathrm{C}<1 & \text { : Dominansi tinggi }
\end{array}
$$

\section{Hasil dan Pembahasan}

\subsection{Mangrove}

\subsubsection{Komposisi Jenis Mangrove}

Hasil analisis vegetasi yang dilakukan pada transek penelitian terdiri atas 3 stasiun (stasiun I,II, dan III). Pada transek stasiun I,II, dan III terdapat III plot, dari hasil pengamatan vegetasi mangrove dilokasi penelitian ditemukan 4 jenis vegetasi mangrove sejati yaitu Bruguiera gymnorrhiza, Rhizopora mucronata, Rhizopora stylosa dan Sonneratia alba.Tabel 1 menyajikan secara lengkap nama species dan jumlah yang ditemukan di lokasi studi.

Tabel 1.

Jumlah species mangrove

\begin{tabular}{|c|l|c|c|}
\hline No & \multicolumn{1}{|c|}{ Nama Spesies } & Jumlah & Family \\
\hline 1 & Bruguiera gymnorrhiza & 60 & Rhizohoraceae \\
\hline 2 & Rhizopora mucronata & 2 & Rhizohoraceae \\
\hline 3 & Rhizopora Stylosa & 26 & Rhizohoraceae \\
\hline 4 & Sonneratia alba & 56 & Rhizohoraceae \\
\hline
\end{tabular}

\subsubsection{Indeks Nilai Penting}

Pada stasiun I ditemukan 2 (dua) spesies mangrove yaitu Bruguiera Gymnorrhiza dan Sonneratia Alba. Untuk 
mengetahui Indek Nilai Penting (INP) suatu jenis vegetasi mangrove dilakukan analisa tentang kerapatan relative jenis (RDi), frekuensi relative jenis (RFi) dan penutupan relative jenis (RCi) sehingga memperoleh hasil Indek Nilai Penting (INP) di Pulau Penyu, Tanjung Benoa Bali. Spesies Bruguiera Gymnorrhiza memiliki Indek Nilai Penting (INP) terendah pada stasiun I dengan nilai sebesar 107.73 dan untuk spesies Sonneratia Alba memiliki Indek Nilai Penting (INP) tertinggi sebesar 192.27.Gambar 2 menampilkan grafik INP masing-masing spesies pada Stasiun 1 .

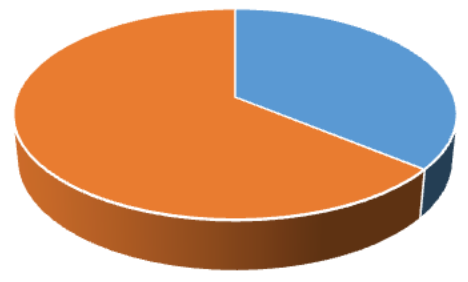

- Bruguiera Gymnorrhiza - Sonneratia Alba

Gambar 2. INP Stasiun 1

Pada stasiun II ditemukan tiga spesies jenis mangrove yaitu : Bruguiera Gymnorrhiza, Rhizopora Stylosa dan Sonneratia Alba. Nilai INP terbesar pada stasiun II adalah spesies Rhizopora Stylosa sebesar 212.66 dikarenakan jenis ini hidup sesuai dengan zonasi serta kecocokan karakteristik jenis substratnya yang mendukung untuk pertumbuhan jenis mangrove ini dan pada stasiun II Rhizopora Stylosa tunggal yang ditemukan sehingga memiliki nilai INP yang tinggi. Bruguiera Gymnorrhiza dan Sonneratia Alba nilai INP sebesar 43.73 dan 43.61 (Gambar 3a). (a)

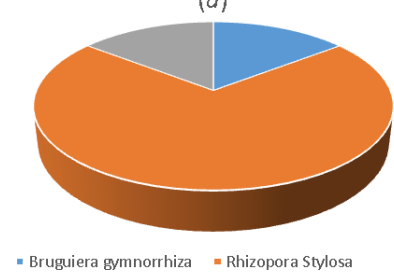

- Sonneratia Alba (b)

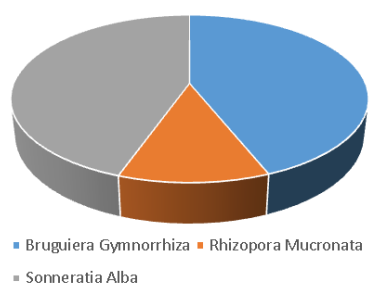

Gambar 3.INP Stasiun 2 dan Stasiun 3

Pada stasiun III ditemukan tiga spesies jenis mangrove yaitu : Bruguiera Gymnorrhiza, Rhizopora Mucronata dan Sonneratia Alba. Nilai INP terbesar pada stasiun 3 adalah jenis Sonneratia Alba sebesar 133.74 dikarenakan dikarenakan jenis ini hidup sesuai dengan zonasi dan substrat lumpur berpasir serta banyak ditemukan pada daerah tepian yang menjorok ke laut. Sonneratia alba adalah jenis tumbuhan pionir yang tidak toleran terhadap air tawar dalam periode lama, menyukai tanah yang bercampur lumpur dan pasir, kadang-kadang pada batuan dan karang (Noor et al, 1999). Bruguiera Gymnorrhiza memiliki nilai INP sebesar 131.78 dan untuk Rhizopora Mucronata memiliki nilai INP terendah sebesar 34.48 (Gambar 3b).

\subsection{Makrozoobenthos}

\subsubsection{Komposisi Jenis Makrozoobenthos}

Berdasarkan hasil penelitian yang dilakukan pada ekosistem hutan mangrove di kawasan Pulau Penyu, Tanjung Benoa Bali, teridentifikasi sebanyak 44 jenis makrozoobenthos yang tersebar pada 3 stasiun dalam 9 titik. Ke 44 jenis makrozoobentos ini terdiri dari 22 genus terdiri dari Cvpraeidae, Naticidae, Cerithiidae, Mathildidae, Mitridae, Columbellidae, Buccinidae, Neritidae, Fasciolariidae, Smaragdinellidae, Littorinidae, Trochidae, Costellariidae, Terebridae, Opisthobranchia, Pyramidellomorpha, Littorinidae, Conidae, Thaididae, Potamididae, Turritellidae, Nassariidae.

\subsubsection{Kelimpahan Makrozoobenthos}

Kelimpahan makrozoobenthos tertinggi pada stasiun I ditunjukan pada Gambar 4, dimana kelimpahan tertinggi pada stasiun I yaitu $385.2 \mathrm{ind} / \mathrm{m}^{2}$. Kelimpahan pada stasiun II yaitu $271.58 \mathrm{ind} / \mathrm{m}^{2}$ dan terendah pada stasiun III yaitu $247.71 \mathrm{ind} / \mathrm{m}^{2}$. Kelimpahan tertinggi pada ketiga stasiun berada pada spesies Cerithium sp kelimpahan terendah berada pada spesies Turritella cochlea dan Cyprae kieneri.

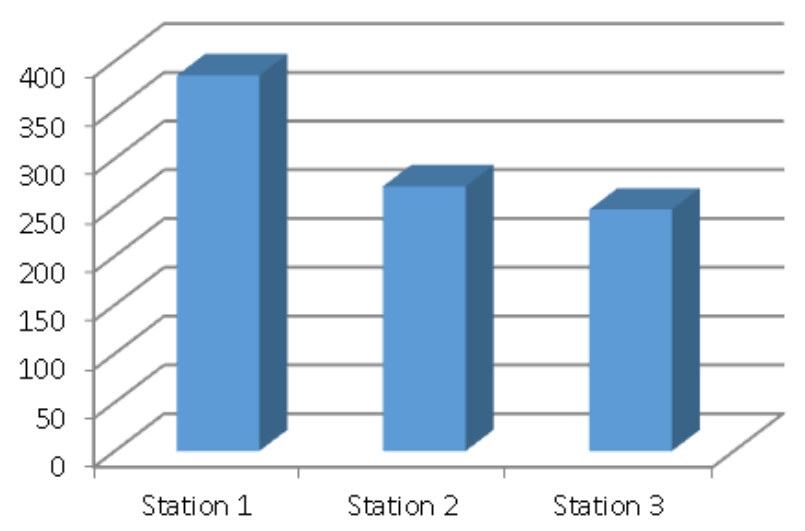

Gambar 4. Nilai Kelimpahan Makrozoobenthos

Jenis makrozoobenthos yang terdapat pada hutan mangrove ini memiliki kelimpahan relative lebih banyak pada Kelas Gastropoda hal ini dapat disebabkan oleh daya tahan tubuh dan adaptasi cangkang yang keras pada spesies tersebut, sehingga lebih memungkinkan untuk bertahan hidup dibandingkan jenis yang lain. Spesies makrozoobenthos yang masuk ke dalam kelas gastropoda mempunyai operkulum yang menutup rapat celah cangkang. Pada saat pasang turun mereka masuk kedalam cangkang lalu menutup celah menggunakan operkulum sehingga kekurangan air dapat diatasi. Sementara kelimpahan tertinggi kedua adalah kelas Bivalvia yang memiliki adaptasi hidup hampir sama dengan gastropoda. Hal ini sesuai dengan pernyataan Nyabakken (1988) bahwa beberapa bivalvia dapat hidup didaerah intertidal karena memiliki kemampuan menutup rapat valvanya untuk mencegah kehilangan air. 


\subsubsection{Indeks Ekologi Makrozoobenthos}

Indeks keanekaragaman (H') makrozoobenthos yang didapatkan terlihat bahwa pada stasiun I berkisar 5,66, pada stasiun II berkisar 4.03, dan pada stasiun III berkisar 4,73. Hal ini menunjukkan bahwa nilai indeks keanekaragaman makrozoobenthos pada hutan mangrove dalam 3 stasiun masuk dalam kategori keragaman tinggi. Keanekaragaman yang tinggi menunjukkan penyebaran jumlah individu tiap jenis yang tinggi dan kestabilan juga tinggi.

Indeks Keseragaman (E) makrozoobenthos didapatkan bahwa pada stasiun I berkisar 2,28, pada stasiun II berkisar 2,12, dan pada stasiun III berkisar 2,04. Hal ini menunjukkan bahwa nilai indeks keseragaman makrozoobenthos pada hutan mangrove dalam 3 stasiun masuk dalam kategori keseragaman tinggi. Apabila mendekati 1 keseregaman tinggi yang menunjukkan tidak ada jenis yang mendominansi.

Indeks Dominansi (C) makrozoobenthos didapatkan pada stasiun I berkisar 0,086, pada stasiun II berkisar 0,591, dan pada stasiun III berkisar 0,597. Hal ini menunjukkan bahwa nilai indeks dominansi makrozoobenthos pada hutan mangrove di stasiun I termasuk dalam dominansi rendah karena nilai dominansi mendekati 0, dan stasiun II dan III masuk dalam kategori dominansi sedang. Gambar 5 menampilkan secara lengkap grafik indeks ekologi makrozoobenthos di kawasan hutan Mangrove Pulau Penyu, Tanjung Benoa.

Hasil indeks keanekaragaman yang tinggi, keseragaman sedang dan dominansi rendah menunjukkan bahwa kondisi komunitas makrozoobenthos di Pulau Penyu menuju kestabilan. Kondisi lingkungan di Pulau Penyu mendukung kehidupan makrozoobenthos, khususnya jenis gastropoda.

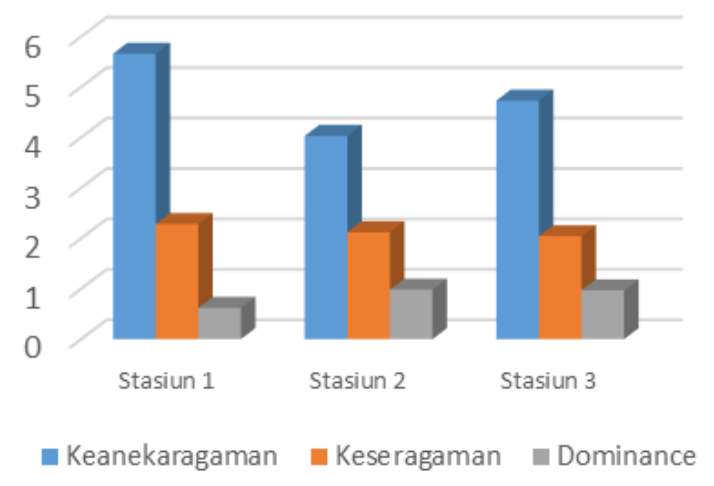

Gambar 5. Grafik Indeks Ekologi Makrozoobenthos

\subsection{Hubungan Mangrove dan Makrozoobenthos}

Hubungan antara mangrove dengan makrozoobenthos dijelaskan dengan metode regresi linier. Nilai Kepadatan Makrozoobenthos merupakan variable bebas (Y) yang terikat hubungannya dengan kerapatan mangrove sebagai peubah bebas $(\mathrm{X})$. Persamaan regresi didapatkan $\mathrm{Y}=$ $60.524 X+119.94$ dengan korelasi 40,05\% dan dapat menjelaskan 16,04\% keragaman makrozoobenthos. Nilai $\mathrm{F}$ hitung yang diperoleh sebesar 1,53 dan $\mathrm{F}$ tabel 3,87, maka dihasilkan nilai $\mathrm{F}$ hitung $<\mathrm{F}$ tabel, sehingga dapat disimpulkan, kerapatan pohon mangrove tidak berpengaruh nyata terhadap kepadatan makrozoobenthos. Gambar 6 menyajikan grafik hubungan antara kerapatan Mangrove dengan kepadatan Makrozoobenthosdi kawasan hutan Mangrove Pulau Penyu, Tanjung Benoa.

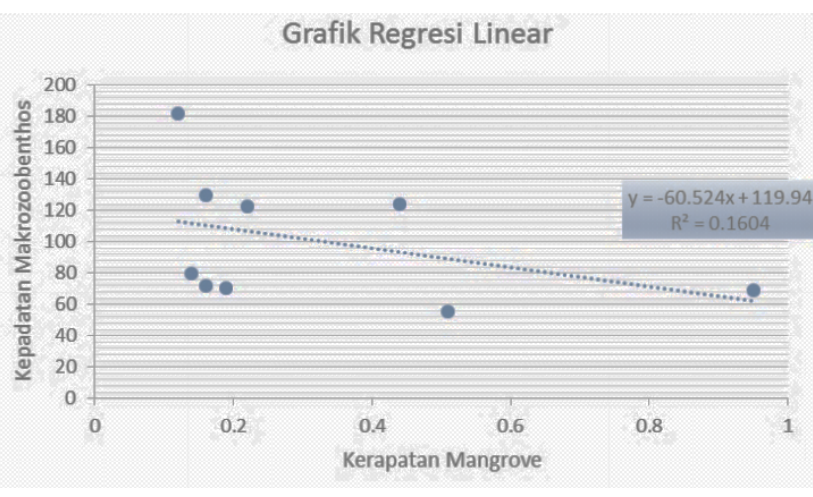

Gambar 6. Grafik Hubungan kerapatan Mangrove-Kepadatan Makrozoobenthos

\section{Simpulan}

1. Mangrove di Pulau Penyu didapatkan 4 jenis, yaitu Bruguiera gymnorrhiza, Rhizopora mucronata, Rhizopora stylosa dan Sonneratia alba. Dengan nilai INP terbesar didapatkan pada jenis Rhizopora stylosa pada stasiun 2, kemudian Bruguiera gymnorrhiza di stasiun 1dan terbesar ketiga Rhizopora mucronata pada stasiun 3.

2. Makrozoobenthos yang ditemukan dan diidentifikasi sebanyak 44 species yang terdiri dari 22 genus, dimana nilai kelimpahan tertinggi didapatkan pada stasiun 1, lalu stasiun 2 dan stasiun 3.

3. Hasil indeks keanekaragaman yang tinggi, keseragaman sedang dan dominansi rendah menunjukkan bahwa kondisi komunitas makrozoobenthos di Pulau Penyu menuju kestabilan. Kondisi lingkungan di Pulau Penyu mendukung kehidupan makrozoobenthos, khususnya jenis gastropoda.

4. Hubungan antara kerapatan mangrove dengan kepadatan makrozoobenthos diperoleh persamaan $\mathrm{Y}=60.524 \mathrm{X}+119.94$ dengan korelasi 40,05\% dan dapat menjelaskan $16,04 \%$ keragaman makrozoobenthos. Nilai $\mathrm{F}$ hitung yang diperoleh sebesar 1,53 dan $\mathrm{F}$ tabel 3,87, maka dihasilkan nilai $\mathrm{F}$ hitung < F tabel, sehingga dapat disimpulkan, kerapatan pohon mangrove tidak berpengaruh nyata terhadap kepadatan makrozoobenthos.

\section{Daftar Pustaka}

Bengen, D. G. (2000). Sinopsis Ekosistem dan Sumberdaya Alam Pesisir. Bogor, Indonesia: Pusat Kajian Sumberdaya Pesisir dan Lautan-Institut Pertanian Bogor.

Bengen, D .G. (2001). Pedoman Teknis Pengenalandan Pengelolaan Ekosistem Mangrove. Bogor, Indonesia: 
Pusat Kajian Sumberdaya Pesisir dan Lautan-Institut Pertanian Bogor.

Brower, J. E., Zar, J. H., \& von Ende, C. (1998). Field and laboratory methods for general ecology. W.M. Brown Company Publ. Dubuqe. Lowa. 194 p

Dahuri, R. (1994). The challenge of sustainable coastal development in East Kalimantan, Indonesia. Coastal Management in Tropical Asia, 12-15.

Nontji, A. (1993). Laut Nusantara. Jakarta, Indonesia: Djambatan.

Noor, Y. R., M.. Khazali, \& I NN, S. (1999). Panduan pengenalan mangrove di Indonesia. Bogor-Indonesia: PKA/WI-IP (Wetlands International-Indonesia Programme).

Nybakken, J. W. (1988). Biologi Laut: Suatu Pendekatan Ekologis. (Terjemahan Muhammad Eidman, Koesoebiono, Dietriech GB, Malikusworo Hutomo dan Sukristijono). Jakarta-Indonesia: Penerbit PT. Gramedia.
Odum, E. P. (1993). Dasar-dasar Ekologi. Diterjemahkan Oleh T. Samingan. Yogyakarta : Gadjah Mada University Press.

Tapilatu, Y., \& Pelasula, D. (2012). Biota Penempel yang Berasosiasi Dengan Mangrove di Teluk Ambon bagian Dalam. Jurnal Ilmu dan Teknologi Kelautan Tropis, 4(2), 267-279.

Ulfah, Y., Widianingsih, W., \& Zainuri, M. (2012). Struktur Komunitas Makrozoobenthos di Perairan Wilayah Morosari Desa Bedono Kecamatan Sayung Demak. Journal of Marine Research, 1(2), 188-196.

Wiyanto, D. B., \& Faiqoh, E. (2015). Analisis vegetasi dan struktur komunitas Mangrove Di Teluk Benoa, Bali. Journal of Marine and Aquatic Sciences, 1(1), 1-7.

Valiela, I., 2001. Marine ecological processes. New York, USA: Library of Congress Catalogy in Publication. Data.

(C) 2016 by the authors; licensee Udayana University, Indonesia. This article is an open access article distributed under the terms and conditions of the Creative Commons Attribution license (http://creativecommons.org/licenses/by/3.0/). 